Research Article

\title{
A Novel Fatigue Damage Model of Rock considering Temperature Effects
}

\author{
Yaoliang Zhu, ${ }^{1,2}$ Jin Yu $\mathbb{D}^{1},{ }^{1}$ Yanyan Cai, ${ }^{1}$ Xin Tang, ${ }^{1}$ Wei Yao, ${ }^{1}$ and Xueying Liu ${ }^{1}$ \\ ${ }^{1}$ Fujian Research Center for Tunneling and Urban Underground Space Engineering, Huaqiao University, Xiamen 361021, China \\ ${ }^{2}$ College of Engineering, Fujian Jiangxia University, Fuzhou 350108, China \\ Correspondence should be addressed to Jin Yu; bugyu0717@163.com
}

Received 14 May 2020; Revised 9 June 2020; Accepted 16 June 2020; Published 10 July 2020

Academic Editor: Fengqiang Gong

Copyright ( 2020 Yaoliang Zhu et al. This is an open access article distributed under the Creative Commons Attribution License, which permits unrestricted use, distribution, and reproduction in any medium, provided the original work is properly cited.

The deformation rules and failure types of rock fatigue damage at different temperatures are quite different, and existing constitutive theory cannot describe them quantitatively. A novel rock fatigue damage model considering the effects of temperature was presented based on phenomenology. In this model, the residual strain method was used to define the fatigue damage, and the Harris attenuation function was introduced to characterize the cyclic damage evolution. The proposed model has considered the influence of the initial damage and temperature, and the model parameters can be easily calculated. The accuracy of the model was verified by comparing the calculated values of cyclic upper strain and fatigue life with previous test results. The physical significance of the model parameters shows that parameter $a$ is related to fatigue stress ratio and lithology, while parameter $b$ is related to temperature. The study has some reference values for the fatigue damage model of rock considering the influence of temperature.

\section{Introduction}

Deep rock engineering is a hot topic in recent years, and there is increasing interest in investigating the characteristics and mechanisms of deep rock failure [1-4]. The surrounding rocks of deep-buried compressed air energy storage (CAES) and tunnel engineering are always in a state of high ground temperature (as shown in Figure 1). This is due to the fact that the ground temperature will increase with the buried depth (the ground temperature gradient is generally $30 \sim 50^{\circ} \mathrm{C} / \mathrm{km}$ [5]), especially for nuclear waste disposal projects, and the temperature of the rock could even reach thousands of degrees. The mechanical properties of various types of rocks such as granite [6], sandstone [7], marble [8], and salt rock [9] have been studied under real-time temperature. The results show that the strength and elastic modulus of rocks decrease with the increase of temperature. The surrounding rocks of the tunnel engineering and CAES are subjected to cycles' loads resulting from the periodic traffic load, earthquake $[10,11]$, and periodic injection and recovery [12]. A lot of research has been done on the fatigue properties of rock under normal temperature [13-18]. In terms of the combination of temperature and cyclic load, Yang and $\mathrm{Hu}$ [19] studied the creep and permeability of red sandstone after high temperature and cyclic load. Wang et al. [20] conducted repeated impacts on the granite after hightemperature cooling and found that the rock dynamic strength and deformability were significantly reduced. Xia et al. [21] pointed out that the peak strain of basalt increases with temperature and cyclic load, but the elastic modulus shows an opposite trend. However, the cycle numbers are limited and the cyclic load is applied after the applied temperature in the aforementioned works, which is different from the rock fatigue damage at real-time temperature. With that in mind, Song et al. [22] and Zhao et al. [23] carried out fatigue tests on salt rock and granite under real-time temperature, respectively. The test results show that temperature causes fatigue damage and affects the deformability of rock. However, the temperature effects are not considered in their fatigue damage models. The fatigue damage model is crucial to assess the safety of the deep rock engineering. It is difficult to make an accurate decision and predict fatigue life based 
on observation data obtained during the construction and operation of underground works without the fatigue damage model.

Most of the fatigue damage models, as shown in Table 1, mainly focus on rock fatigue damage at room temperature, and the damage variables are mainly defined by the elastic modulus, energy, and plastic strain. This may lead to some discrepancy when using the model. For example, the initial damage is not considered [24-26] or the initial damage $D_{0}$ is independent of the damage model [27, 28], making it inappropriate to be used to predict fatigue life. Moreover, the model parameters are always obtained through data fitting, which requires a large amount of calculation. For example, the damage models used by Xie et al. [24] and Liu et al. [26] require input parameters like unloading elastic modulus and residual plastic deformation in each cyclic stress-strain curve, or the energy consumed, while the model developed by Xiao et al. [27] needs the position of $x_{0}$. To solve the above limits, a new fatigue damage model considering the influence of temperature was established by introducing Harris attenuation function. The initial damage is dependent on the damage model; thus, the fatigue life can be predicted at the beginning of the cycle. The applicability of the model was verified by comparing with previous experimental data. This paper is of great significance to understand the fatigue damage law of rock under real-time temperature.

\section{Theoretical Analysis}

2.1. Fatigue Damage Model. In solid mechanics, materials containing various defects can be regarded as a continuous medium containing "microdamage field," which is employed to describe the formation and development process of microdamage. Damage variable $D$ is defined as the ratio of the damaged area $\left(A_{n}\right)$ in the rock to the total area $(A)$ to quantify the damage and deterioration degree inside the materials, which can be expressed as follows:

$$
D=\frac{A_{n}}{A} \text {. }
$$

Figure 2 is the schematic diagram of the fatigue test, and the numbers of 0,1 , and $i$ represent the numbers of cycles in the aforementioned damage model. As shown in Figure 3, curve $I$ represents the situation that when the maximum stress is lower than the fatigue threshold, the irreversible deformation will remain stable for a long time, while curves $I I$ and III correspond to the cases where the plastic strain keeps increasing until rock failure. The increase of plastic strain indicates the initiation of cracks in the rock or, put in another way, the increase of damage area; thus, a positive correlation could be assumed between the plastic strain and damage. Therefore, it may be feasible to characterize fatigue damage by the plastic strain.

When calculating the fatigue damage via variables, it is necessary to take the effect of initial damage into account $[27,28]$. The residual strain method is expected to meet the requirement, the expression of which is as follows:

$$
D_{n}=\frac{\varepsilon_{\mathrm{ln}}}{\varepsilon_{\mathrm{lc}}}
$$

where $D_{n}$ is fatigue damage after $n$ cycles and $\varepsilon_{\ln }$ and $\varepsilon_{\mathrm{lc}}$ are the residual axial strain after $n$ cycles and the ultimate axial residual strain at fatigue failure, respectively.

The fatigue damage law calculated by the residual strain method corresponding to the three curves in Figure 3 can be seen in Figure 4.

Different initial damage values and fatigue damage evolution rules corresponding to the different types of fatigue in Figure 3 can be seen in Figure 4. Previous researchers $[29,30]$ often use the Weibull distribution and normal distribution functions to establish rock damage statistical models by taking the rock axial strain or yield criterion as the microelement strength, thus combining continuous damage theory with statistical strength theory. However, the size effect of the Weibull distribution makes it unsuitable in quasibrittle materials, while the normal distribution will have negative rock strength and parameters, which is inconsistent with the actual situation. Phenomenology $[27,28]$ is a research method that describes phenomena through "direct knowledge." With the aim of establishing a damage model to represent the three types of fatigues, as well as incorporating the initial fatigue damage into the fatigue damage model, the starting point of plastic deformation (the endpoint of the linear elastic stage) is assumed as the 0th cycle, thus allowing the initial damage of the three types of cycles to be classified as 0 . For the rock that has fatigue failure, the fatigue damage of the rock increases from 0 to 1, as shown in Figure 4. Furthermore, a transition variable $S_{n}$ is introduced as follows:

$$
S_{n}=1-D_{n}
$$

Thus, a red attenuation curve can be observed in Figure 4. The attenuation function describing rock fatigue damage should meet the following conditions to ensure that the function parameters have a certain significance: (1) the function should be a decay function; (2) the attenuation rate should be a variable that can meet different types of fatigue damage; and (3) the parameter of the function should be greater than 0 , which has a clear physical significance.

Common decay functions include linear decay, exponential decay, and Gaussian decay, as shown in Figure 5(a). However, some problems exist in these functions. For example, the decay rate of the linear decay function is constant, while the decay rate in exponential decay function increases first and then slows down. Moreover, the calculation of Gaussian decay function is relatively complicated, and the parameter can be any real number, which is inconsistent with the actual situation. These attenuation functions are unable to reflect the fatigue failure of different types of rocks. The Harris attenuation function, as shown in the following equation, has only two parameters, which are greater than 0 . Different types of attenuation forms can be obtained as shown in Figure 5(b) by changing the values of the two parameters, which can meet different types of fatigue damage: 


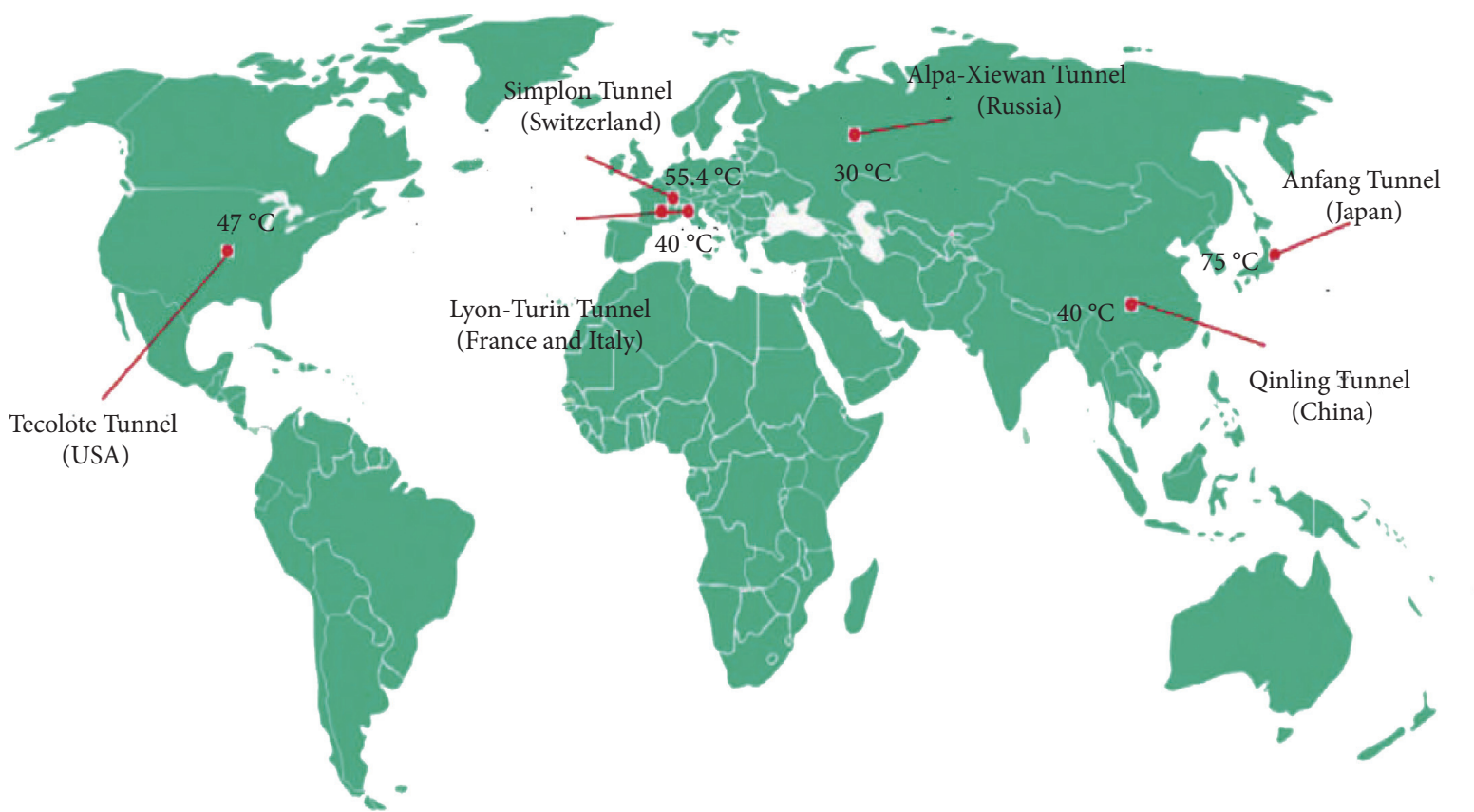

FIGURE 1: Geothermal values of tunnels in some countries around the world [1].

TABLE 1: Comparison of damage models.

\begin{tabular}{lccc}
\hline Author & Damage evolution equations & Damage variable & Initial damage \\
\hline Xie et al. [24] & $D=1-\left(\varepsilon-\varepsilon^{\prime} / \varepsilon\right)\left(E^{\prime} / E\right)$ & Elastic modulus method & 0 \\
Wang et al. [25] & $D=1-\left[1-a_{0}\left(\left((\Delta \sigma)^{\left((1-m) / n_{0}\right)}\right) / f^{b_{0}}\right)\left(N / N_{f}\right)^{c}\right]^{n_{0} /\left(1+n_{0}\right)}$ & Residual strain method \\
Liu et al. [26] & $D=1-\exp \left[-B\left(\left|Y-Y_{0}\right|\right)^{\left(1 / k_{0}\right)} / Y^{*}\right]$ & Energy dissipation method & 0 \\
Xiao et al. [27] & $D=D_{0}+\alpha[(\beta / \beta-N)-1]^{(1 / p)}$ & Residual strain method \\
Xiao et al. [28] & $D=D_{0}+a_{1} \ln (N)+b_{1} \cdot e^{\left(\left(\ln (N)-x_{0}\right) / p\right)}$ & Residual strain method & $D_{0}$ \\
\hline
\end{tabular}

$D$ is the fatigue damage variable, $D_{0}$ is the fatigue initial damage, $n$ is the cyclic number, $N_{f}$ is the fatigue life, $E$ and $E^{\prime}$ are the unloading stiffness and initial elastic modulus in the fatigue loading and unloading process of elastoplastic damaged materials, and $\varepsilon$ and $\varepsilon^{\prime}$ are the total strain and the residual plastic strain after unloading, respectively. $n_{0}$ is the hardening index, $a_{0}, b_{0}, c$, and $m$ are the material constants, respectively. $f$ is the frequency; $\Delta \sigma$ is the amplitude of stress. $B$ and $k_{0}$ are the mechanical constants. $Y^{*}$ is an energy release per unit volume with the dimension $1 \mathrm{~J} / \mathrm{mm}^{3} ; Y$ is the released damage strain energy during a loading-unloading cycle. $\alpha$ is instability proportion factor, $\beta$ is the instability factor, and $p$ is instability velocity factor. $a_{1}$ is the linear damage rate, $b_{1}$ is the instability proportion factor, and $x_{0}$ represents the critical instability center.

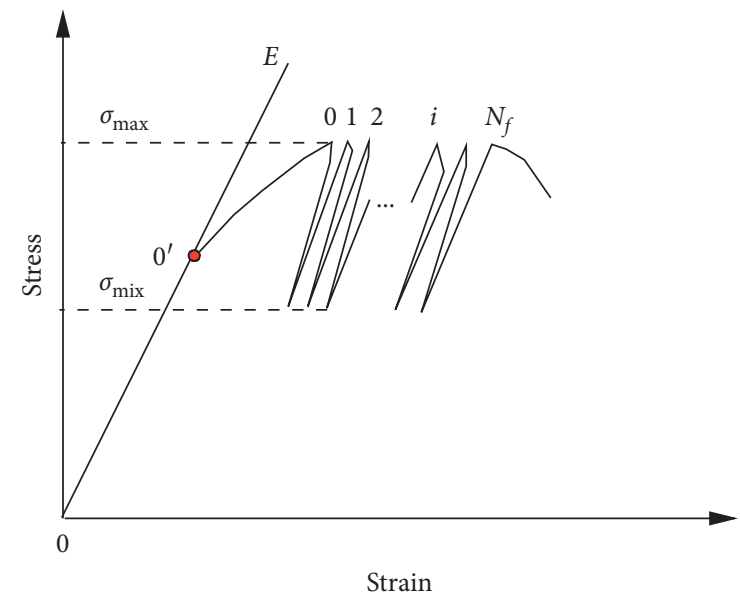

FIGURE 2: Schematic diagram of fatigue test.

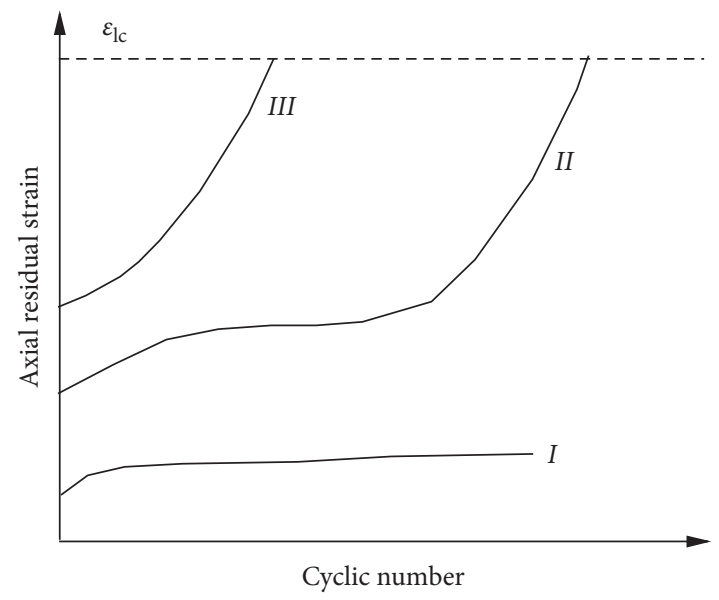

Figure 3: Classification of development curves of axial residual strain. 


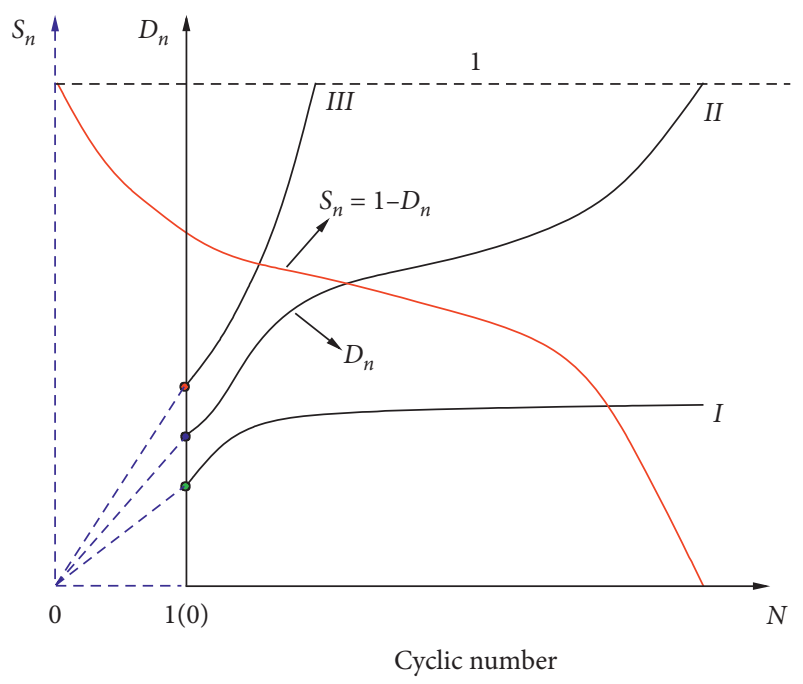

FIgURE 4: Fatigue damage law.

$$
S(F)=\frac{1}{1+a F^{b}}
$$

where $a$ and $b$ are parameters greater than 0 and $F$ is the independent variable of the model.

To build the relationship between damage value and cyclic number, assume that $F=\left(n /\left(N_{f}-n\right)\right)$; thus, the fatigue damage value increases from 0 to 1 , while $n$ increases from 0 to $N_{f}$. The fatigue damage model based on the Harris attenuation function can be expressed as follows:

$$
D_{n}=\frac{\varepsilon_{\ln }}{\varepsilon_{l c}}=1-S\left(\frac{n}{N_{f}-n}\right)=1-\frac{1}{1+a\left(n /\left(N_{f}-n\right)^{b}\right)} .
$$

\subsection{Fatigue Damage Model considering Temperature Effects.} Figure 6 shows the results of the salt rock fatigue test conducted by Song et al. [22] at real-time temperature. The test temperature was set at $13^{\circ} \mathrm{C}, 30^{\circ} \mathrm{C}$, and $60^{\circ} \mathrm{C}$, respectively, and the upper and lower limits of fatigue stress are $90 \%$ and $20 \%$ of the peak stress for each temperature (only the results of $T=30^{\circ} \mathrm{C}$ in literature [22] are given, due to the limitation of space).

As shown in Figure 6, the stress-strain curve has undergone numerous thinning-dense-thinning cycles, which indicates that with the increase of cycle times, the growth of internal damage of rock shows a fast-slow-fast development law and the fatigue life of salt rock increases with increasing temperature. The fatigue life at three temperatures $\left(13^{\circ} \mathrm{C}\right.$, $30^{\circ} \mathrm{C}$, and $60^{\circ} \mathrm{C}$ ) is 9,38 , and 44 times, respectively. It can also be seen that the upper strain limit of the fatigue curve is controlled by the uniaxial compression curve.

The results show that the damage development of rock materials is linearly related to the cumulative plastic strain rate [31]; that is,

$$
\dot{D}=-\frac{Y}{s_{0}} \dot{\varepsilon}_{l},
$$

where $Y$ is the released damage strain energy during a loading-unloading cycle, $\dot{\varepsilon}_{l}$ is the growth rate of residue strain which is caused by the fatigue load, and $s_{0}$ is the material constant.

Considering the simplification of the above relationship, the following assumptions are made:

(1) $\varepsilon_{l}$ is independent of $Y$

(2) The change of temperature during cyclic loading is ignored; then, the damage caused by temperature $D_{T}$ is taken as the initial damage

Thus,

$$
\int_{D_{T}}^{D_{n, T}} \mathrm{~d} D=\int_{0}^{\varepsilon_{\mathrm{ln}}}\left(-\frac{Y}{s_{0}}\right) \mathrm{d} \varepsilon_{l}
$$

The solution of equation (7) is

$$
D_{n, T}-D_{T}=-\frac{Y}{s_{0}} \varepsilon_{l n} .
$$

When $n=N_{f}, \varepsilon_{l \mathrm{~N}}=\varepsilon_{\mathrm{lc}}$; then, $D_{n, T}=1$, and

$$
-\frac{Y}{s_{0}}=\frac{1-D_{T}}{\varepsilon_{\mathrm{lc}}} \text {. }
$$

Substituting (9) into (8), a novel fatigue damage model for rock incorporation the effects of temperature can be written as follows:

$$
D_{n, T}=\frac{\varepsilon_{\mathrm{ln}}}{\varepsilon_{\mathrm{lc}}}\left(1-D_{T}\right)+D_{T},
$$

where $D_{n, \mathrm{~T}}$ is the total fatigue damage which considers temperature effects; $D_{T}$ is the damage caused by temperature, which can be obtained according to $[32,33]$ :

$$
D_{T}=1-\frac{E_{\mathrm{T}}}{E_{0}}
$$

Substituting (5) into (10) gives

$D_{n, T}=\left(1-D_{T}\right)\left(1-\mathrm{S}\left(\frac{n}{N_{f}-n}\right)\right)+D_{T}=D_{n}+D_{T}-D_{n} D_{T}$.

It can be seen from equation (12) that by considering the temperature and fatigue load, rock damage will be influenced by the fatigue load and temperature. The influence is not a simple linear superposition and will be affected by $D_{n}$ and $D_{T}$ at the same time.

2.3. Parameter Acquisition of the Fatigue Damage Model. The value of $a$ and $b$ can be determined by data fitting which is the same as the method mentioned above, or can be solved by a two-point calculation method. The specific method is as follows:

When $n=\left(N_{f} / 2\right)$, equation (5) can be transformed into

$$
D_{\left(N_{f} / 2\right)}=\frac{\varepsilon_{(l N / 2)}}{\varepsilon_{l c}}=1-\frac{1}{1+a} \text {. }
$$




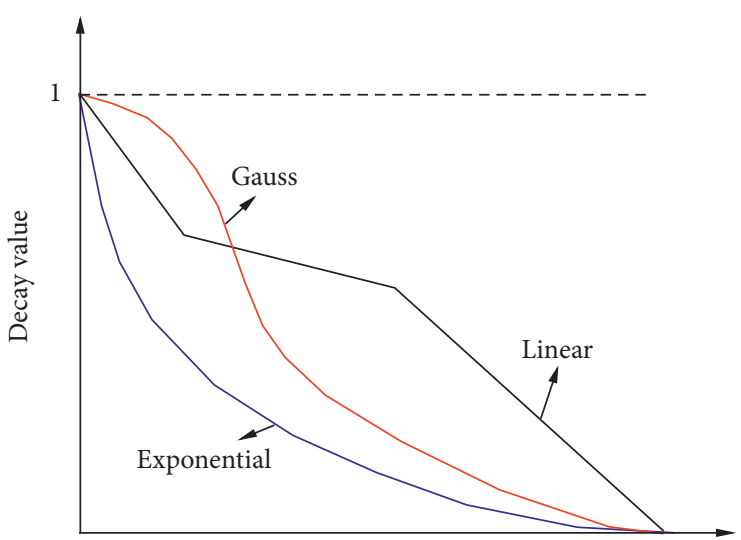

Cyclic number

(a)

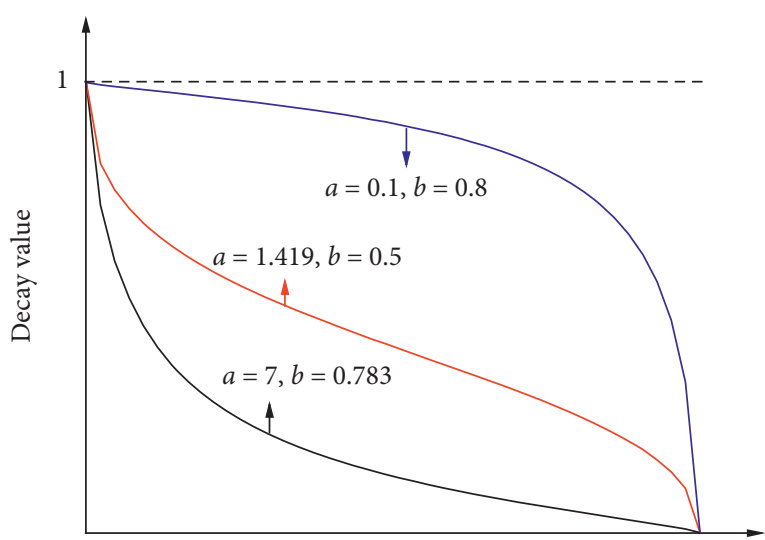

Cyclic number

(b)

FIgURE 5: Comparison of attenuation functions.

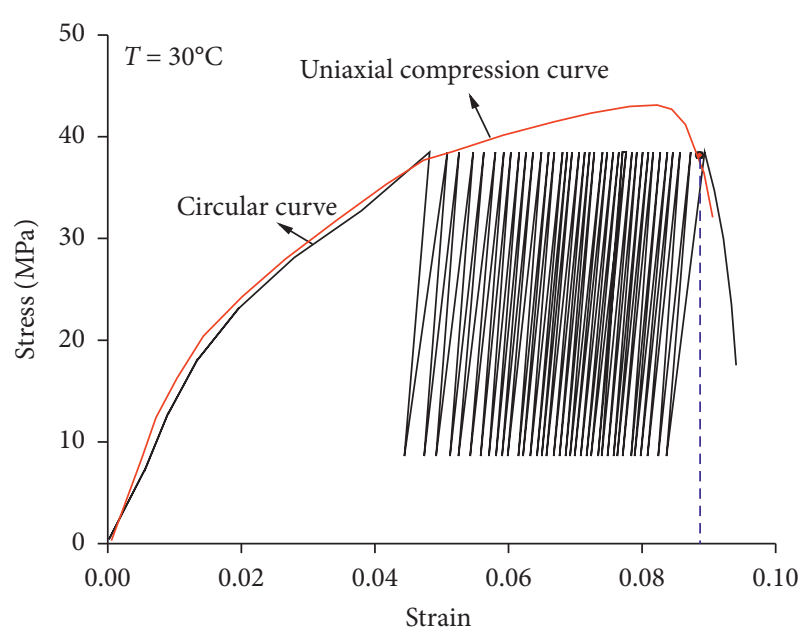

FIGURE 6: Fatigue curve of salt rock [22].

Thus,

$$
a=\frac{1}{1-D_{\left(N_{f} / 2\right)}}-1
$$

And then substituting equations (14) into (5), the value of $b$ can be calculated as follows:

$$
b=\log _{B} A,
$$

where $A=(1 / a)\left(1 /\left(1-D_{n}\right)-1\right), B=(n /(N-n)), \quad D_{\left(N_{f} / 2\right)}$ and $D_{n}$ are the fatigue damage at the $\left(N_{f} / 2\right)$ and arbitrary times, respectively.

\section{Fatigue Model Verification and Analysis}

3.1. Fatigue Model Verification. Figure 7 shows the developments of the upper strain of two rocks with the number of cycles, while the test values $[22,23]$ are compared with the values obtained by the fitting and the two-point calculation methods. The parameter $b$ is calculated using the first cycle when using the calculation method, and the model parameters and correlation coefficients are shown in Table 2. It can be found that the upper strain calculated by the damage model in this paper is very consistent with the test value, and the correlation coefficients are all above 0.96 .

3.2. Effect of Temperature on Fatigue Damage. The influence of temperature on fatigue damage can be calculated from the following formula:

$$
\begin{aligned}
D_{n}(\Delta T) & =D_{n}\left(T_{1}\right)-D_{n}\left(T_{2}\right), \\
D_{n, T}(\Delta T) & =D_{n, T 1}-D_{n, T 2},
\end{aligned}
$$

where $D_{n}(\Delta T)$ and $D_{n, T}(\Delta T)$ indicate the inhibitory effect of temperature on the $n$th fatigue damage and total damage when the temperature increases from $T_{1}$ to $T_{2}$, respectively. Positive value indicates inhibition, while negative value means promotion.

As shown in Figure 8, fatigue damage $D_{n}$ increases nonlinearly with the increase of cyclic number, regardless of the temperature level, and the cyclic damage curve becomes stable with the increase of temperature. The shaded part in Figure 8(a) represents the effect of temperature on the fatigue damage. The results show that the temperature greatly inhibits the development of fatigue damage compared with temperature $13^{\circ} \mathrm{C}$. But when the temperature increases from $30^{\circ} \mathrm{C}$ to $60^{\circ} \mathrm{C}$, the temperature promotes the fatigue damage first and then suppresses it. Figure 8(b) is the total damage evolution rule of salt rock after considering temperature damage $D_{T}$, where $n=0$ and $n=1$ represent temperature damage and initial fatigue damage, respectively. Temperature damage of salt rock at $60^{\circ} \mathrm{C}$ is much larger than that at the other two temperatures, which is mainly because that the salt rock is very sensitive to temperature and its mechanical properties will deteriorate with the increase of temperature. Similarly, it can be seen from Figure 8 (b) that when the temperature increases from $30^{\circ} \mathrm{C}$ to $60^{\circ} \mathrm{C}$, the temperature promotion effect gradually decreases from 0.089 to 0 as the number of cycles increases, which indicates that the cyclic load also has an inhibitory effect on temperature damage. 


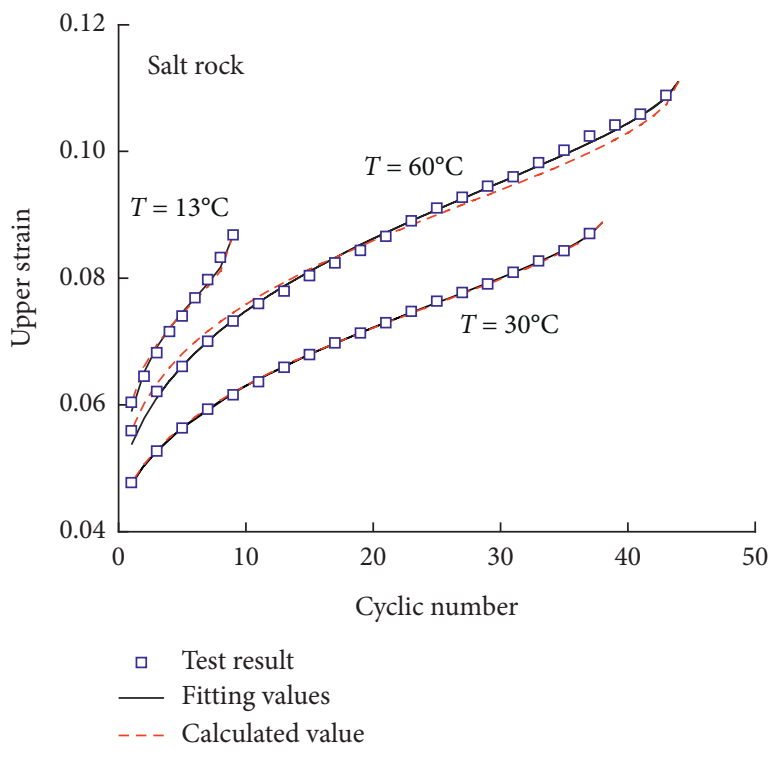

(a)

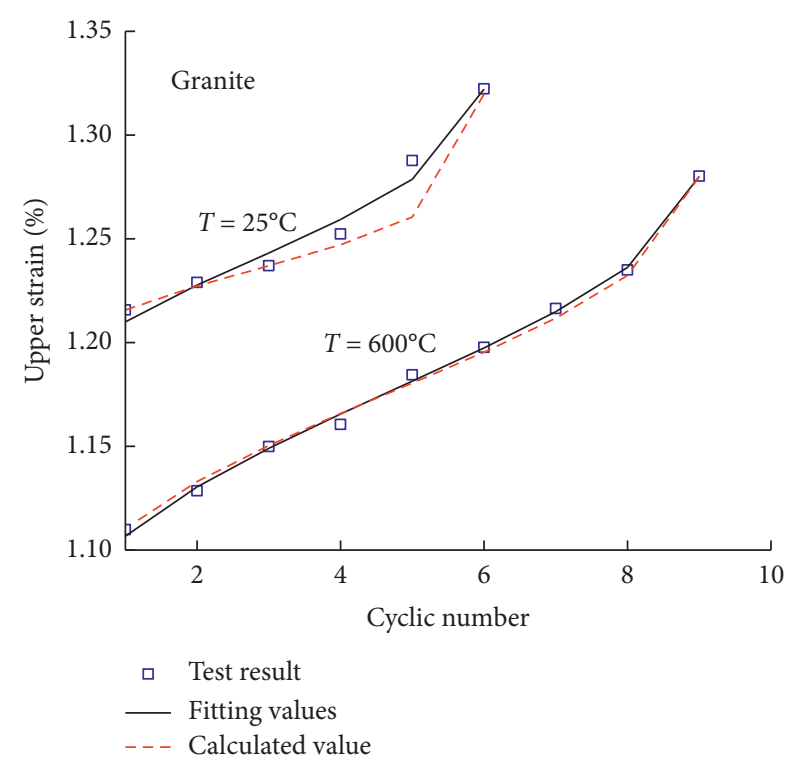

(b)

FIGURE 7: Upper strain of rock fatigue.

TABLE 2: Fatigue damage model parameter values.

\begin{tabular}{lccc}
\hline $\mathrm{T} /{ }^{\circ} \mathrm{C}$ & $a$ & $b$ & $R^{2}$ \\
\hline $13[22]$ & $3.17(3.19)$ & $0.5(0.55)$ & $0.99(0.99)$ \\
$30[22]$ & $1.66(1.67)$ & $0.7(0.71)$ & $0.99(0.99)$ \\
$60[22]$ & $1.80(1.86)$ & $0.60(0.68)$ & $0.99(0.99)$ \\
$25[23]$ & $0.73(0.87)$ & $0.40(0.63)$ & $0.96(0.98)$ \\
$600[23]$ & $1.12(1.12)$ & $0.59(0.63)$ & $0.99(0.99)$ \\
\hline
\end{tabular}

Note. The parameter values and correlation coefficients are obtained by the fitting method provided in the study in brackets.

3.3. Comparison of Fatigue Damage Models. As can be seen in Figure 9, no matter at what temperature, the damage of salt rock calculated by the method in [24] starts from 0 and then increases to 1 with increasing cycles. However, the damage calculated by the method in this paper is larger than that in [24] at the beginning. The reason is that the method proposed in this paper not only considers the influence of temperature, but also takes into account the initial fatigue damage. The damage model in this paper can better characterize the evolution law of rock fatigue damage considering temperature load since the temperature damage and initial fatigue damage exist in real case.

3.4. Fatigue Life Prediction. Fatigue life is unknown before the rock failure; thus, the damage expression should be normalized. Assuming that $k=\left(n / N_{f}\right)$, equation (5) can be transformed into

$$
\begin{aligned}
D_{n} & =\frac{\varepsilon_{\mathrm{ln}}}{\varepsilon_{\mathrm{lc}}}=1-S\left(\frac{n}{N_{f}-n}\right)=1-S\left(\frac{k}{1-k}\right), \\
\varepsilon_{\mathrm{lc}} & =\varepsilon_{c}-\frac{\sigma_{\max }}{E_{T}},
\end{aligned}
$$

where $\varepsilon_{c}$ and $\varepsilon_{l_{c}}$ are the total strain and residual strain corresponding to the upper stress level, which can be obtained from uniaxial compressive stress-strain curves $[22,27]$, and $\sigma_{\max }$ is the upper stress level.

Thus, the prediction formula of fatigue life can be written as

$$
N_{f}=n \times\left(\frac{1+m}{m}\right)
$$

where $m=\left(D_{n} / a\left(1-D_{n}\right)\right)^{(1 / b)}$.

Based on the test result of [22], the case at $T=30^{\circ} \mathrm{C}$ is taken as an example to verify the calculation process. The upper stress is $\sigma_{\max }=44 \times 0.9=39.6 \mathrm{MPa}$, and the total strain on the uniaxial compression full stress-strain curve is $\varepsilon_{c}=0.0894$; the elastic modulus is $E_{30}=915 \mathrm{MPa}$, so the residual strain is $\varepsilon_{\mathrm{lc}}=0.04612$. The residual strain at the beginning of cycle is $\varepsilon_{11}=0.005435$; thus, the fatigue damage value is $D_{1}=0.1178$. Substituting this fatigue damage value into (20), the fatigue prediction life is 37.47 , which is very close to the test result 38 . The fatigue prediction life at other temperatures is shown in Figure 10, in which the numerical value represents the error rate between the predicted value and the actual value. According to the comparison results, the predicted value is very close to the experimental value, and the maximum error is no more than $5 \%$, which indicates that the fatigue life prediction formula can better predict the fatigue life under real-time temperature.

\section{Model Parameter Impact Analysis}

Figure 11 shows the effect of model parameters $a$ and $b$ on the development of fatigue damage. The test data are taken from [22] and the temperature value is $60^{\circ} \mathrm{C}$. It can be seen from Figure 11(a), when $b$ is kept constant, larger $a$ will produce larger early fatigue damage. Fatigue damage 


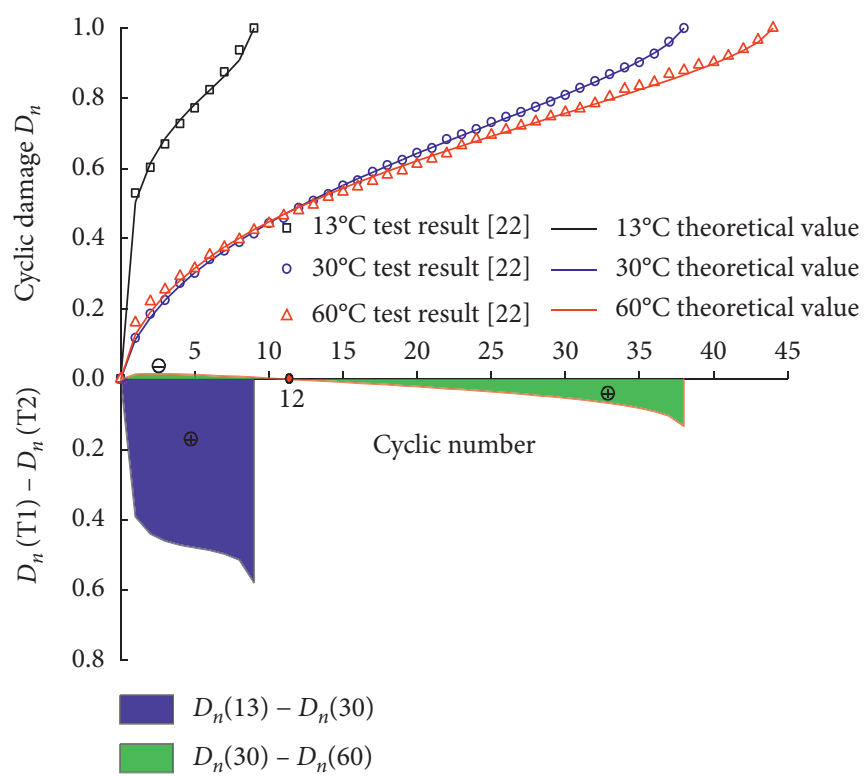

(a)

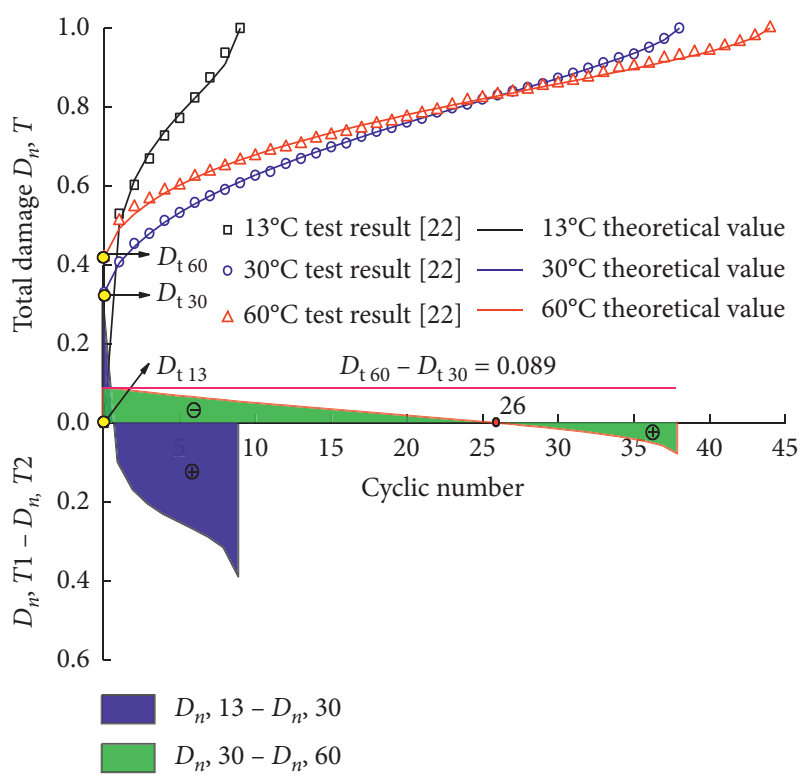

(b)

Figure 8: Evolution law of fatigue damage under real-time temperature.

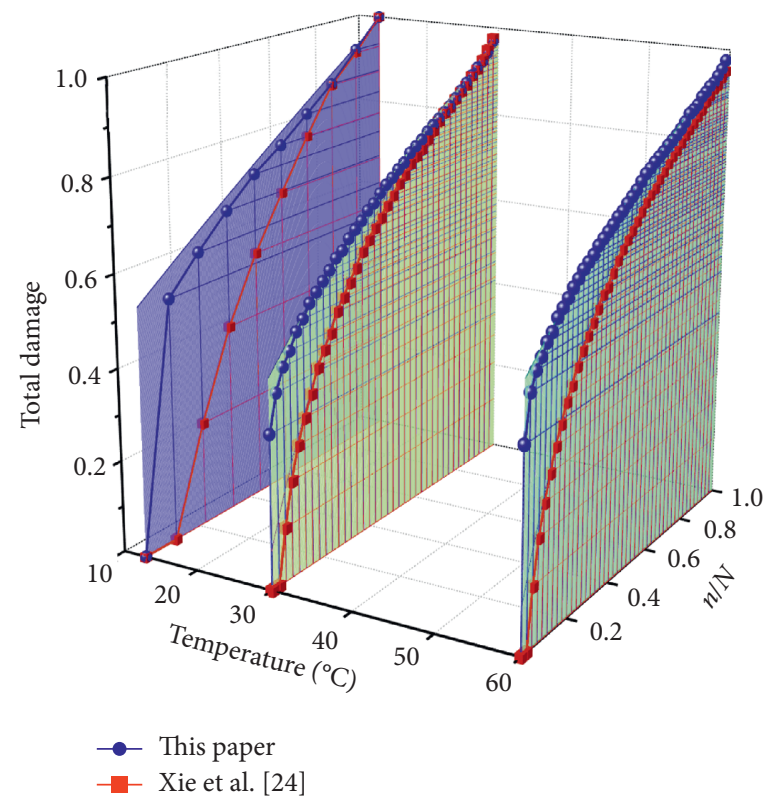

Figure 9: Comparison of fatigue damage evolution.

growth rate increases with the increase of $a$, which is consistent with III growth pattern as shown in Figure 3. Similarly, it can be seen from Figure 11(b) that when the parameter $a$ is constant, the initial fatigue damage increases with the decrease of the parameter $b$, and the longer steady stage indicates that the plastic deformation ability of rock is improved. Compared with Figure 8(b), it can be found that the initial fatigue damage of salt rock increases by considering the effect of temperature; meanwhile, the viscoplastic deformation ability of salt rock is also improved. This reveals that the influence law of parameter $b$ and temperature on total damage is consistent.

\section{Discussion}

Two cases in $[22,23]$ with temperature of $13^{\circ} \mathrm{C}$ and $600^{\circ} \mathrm{C}$ are selected to verify the proposed model. The cyclic number is set as 9 and the fatigue damage $D_{4}, D_{5}$, and $D_{4.5}$ (the average value of two points) are input into (14) and (15) to produce the relative error of the upper strain calculated by different parameters, as shown in Figure 12. The model parameters are summarized in 


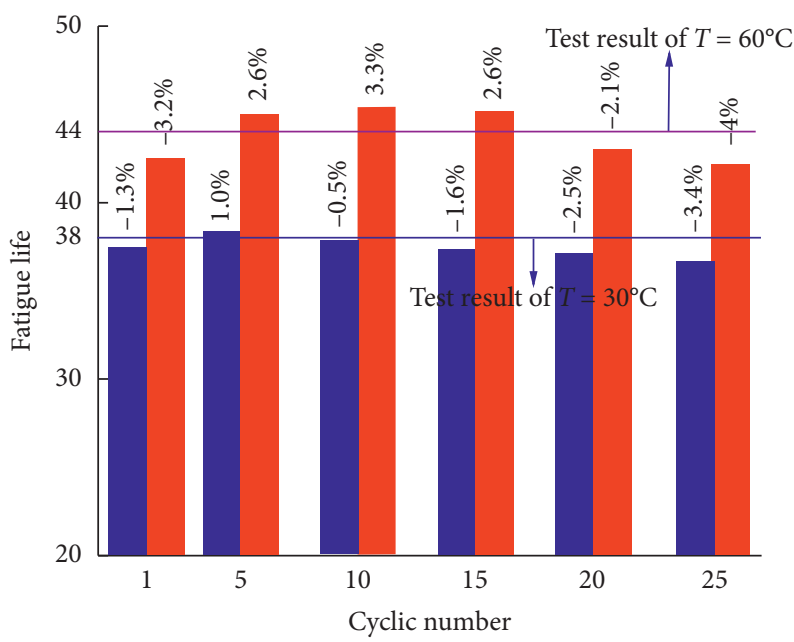

$\mathrm{T}=30^{\circ} \mathrm{C}$

$T=60^{\circ} \mathrm{C}$

Figure 10: Prediction results of fatigue life.

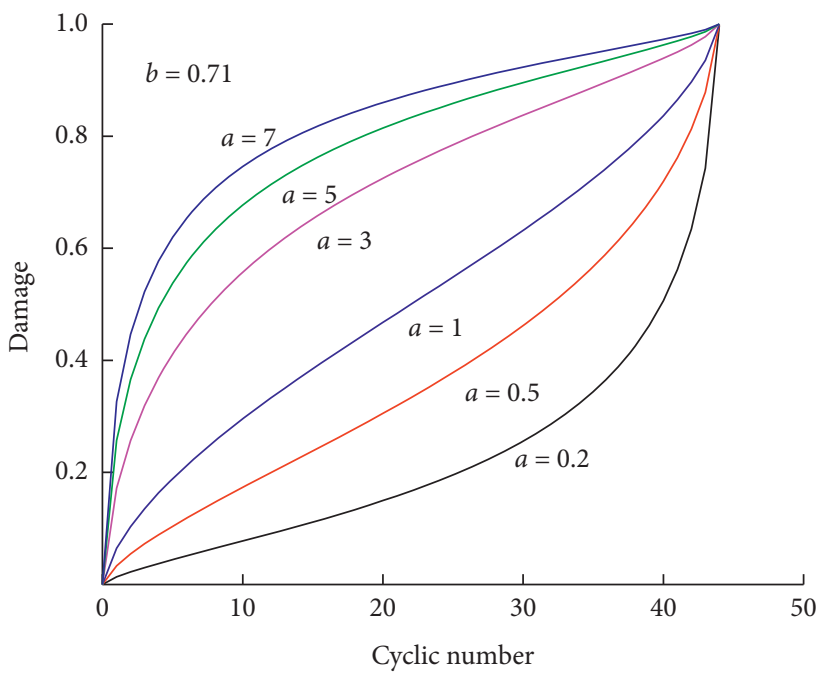

(a)

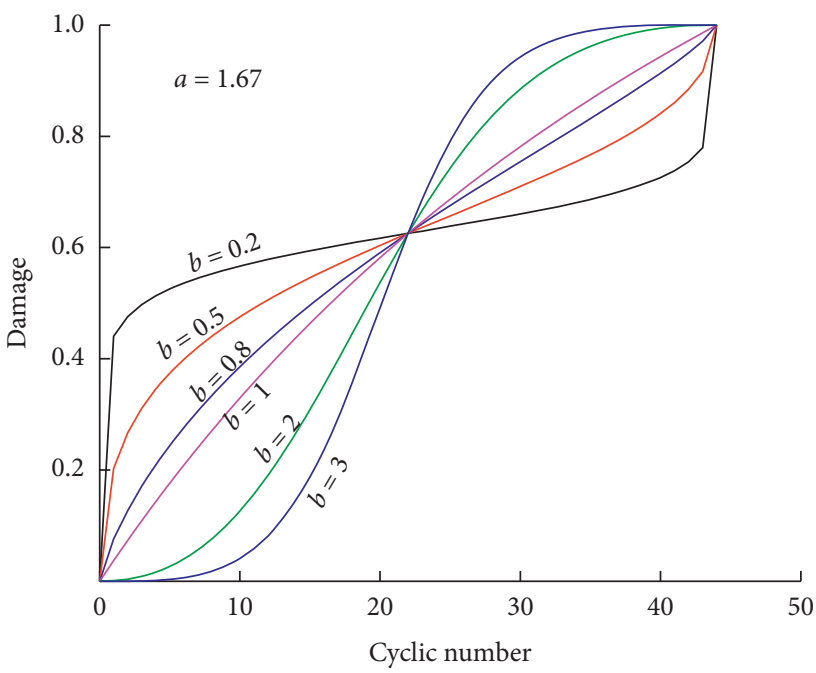

(b)

FiguRE 11: Impact of model parameters.

Table 3. It can be found that the model parameter $a$ and $b$ increase with the increase of $D_{N f / 2}$, and the fitting value of the parameter $a$ is closer to the corresponding result of $D_{4.5}$. However, the fitting value of $b$ is closer to the result of $D_{5}$ for the salt rock, while being $D_{4.5}$ for the granite. Residual strain growth rate (single plastic strain increment) in Figure 12 also indicates that the process from the fourth to the fifth cycle is the inflection point of the two kinds of rocks, while the difference is that the inflection point for the rock salt indicates the minimum value and the inflection point for the granite represents the maximum value. This shows that the characteristics of rock residual strain growth should also be considered when determining the parameters. However, from the perspective of the correlation coefficient, the calculated values are highly consistent with the experimental values when the average values of adjacent points are taken to calculate the model parameters. 


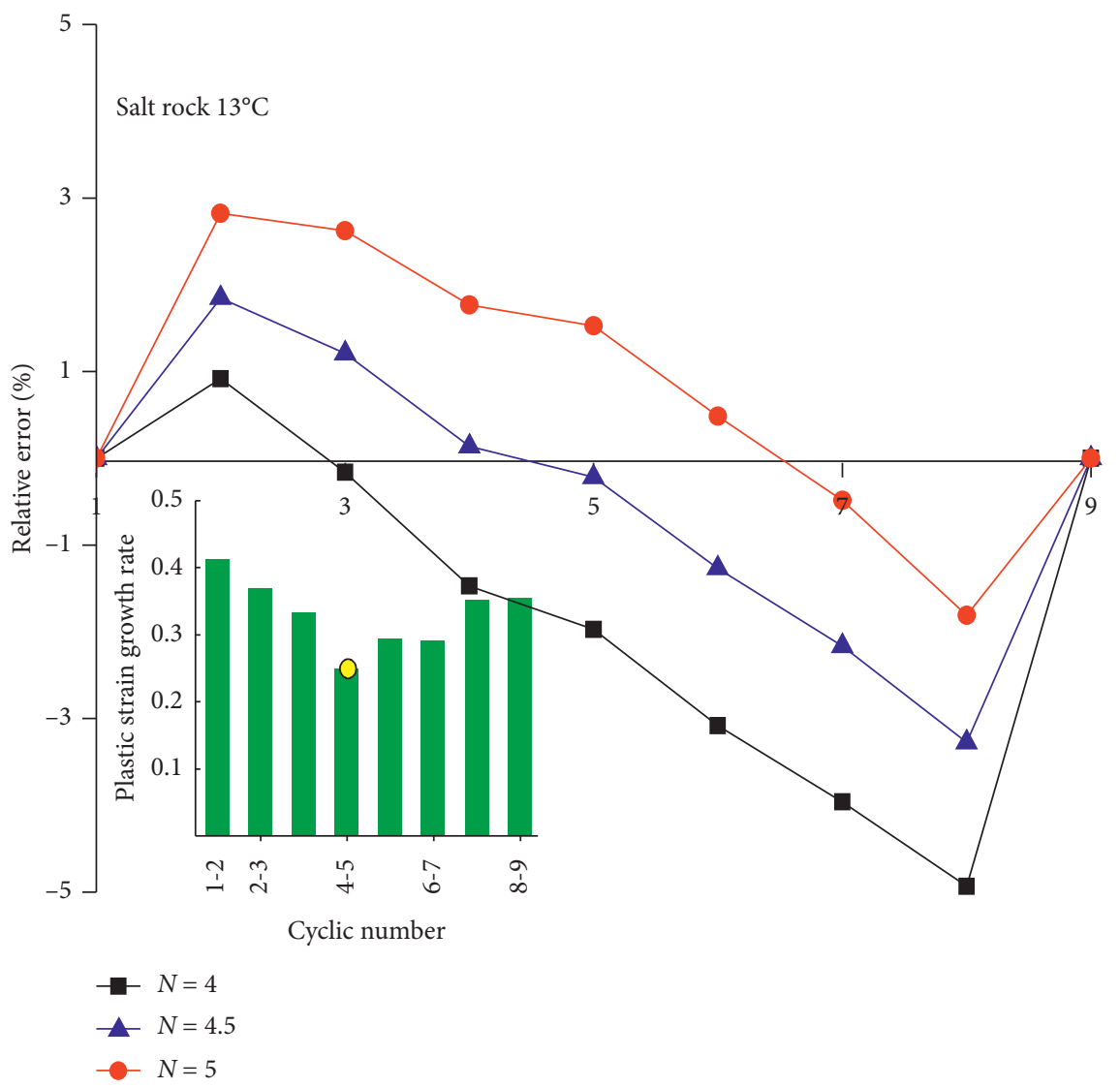

(a)

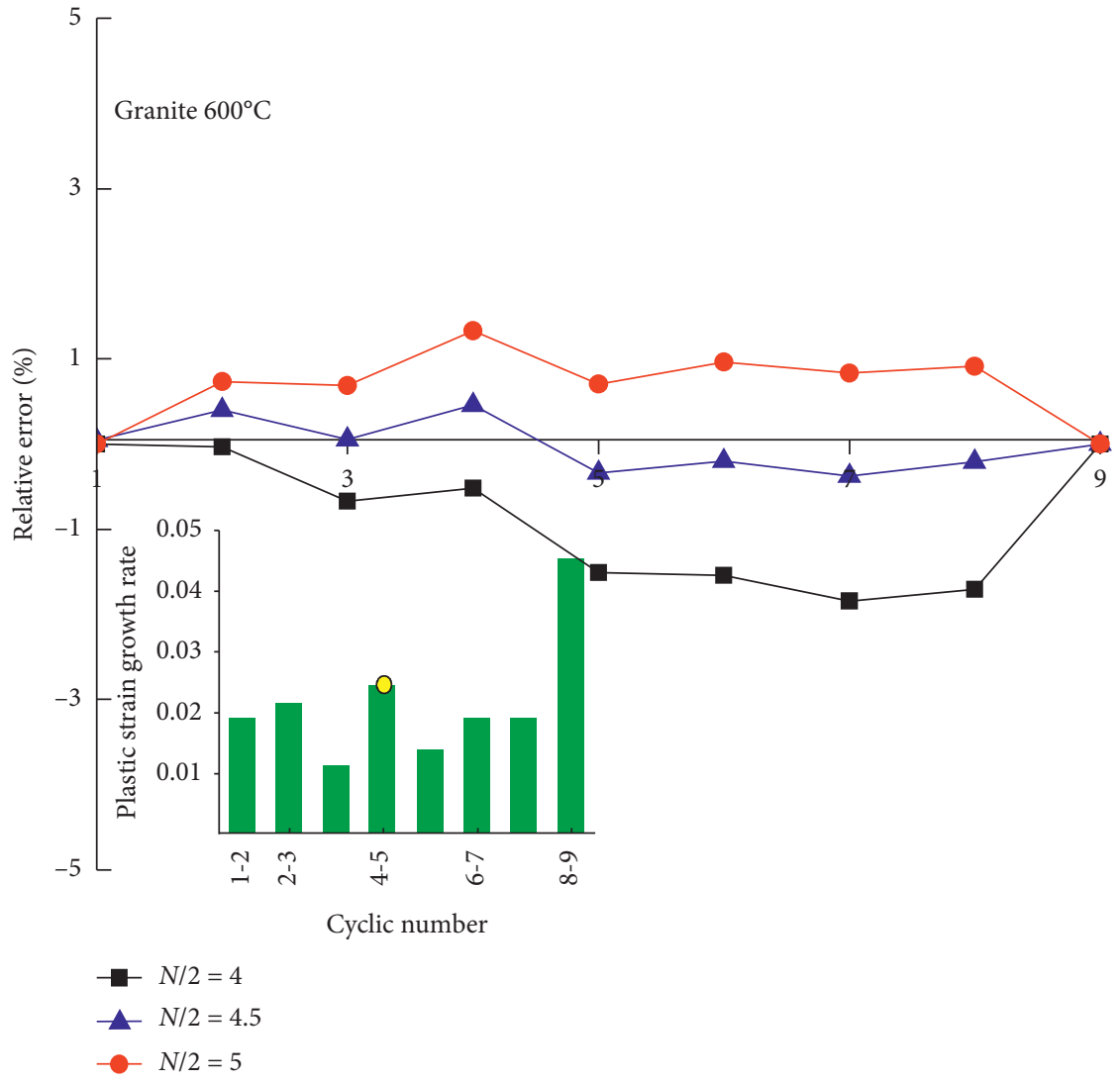

(b)

FIgURE 12: Relative error of upper strain. 
TABLE 3: Model parameters for different midpoint calculations.

\begin{tabular}{lcccc}
\hline$T\left({ }^{\circ} \mathrm{C}\right)$ & $N / 2$ & $a$ & $b$ & $R^{2}$ \\
\hline & 4 & 2.678 & 0.417 & 0.986 \\
$13[22]$ & 4.5 & 3.002 & 0.472 & 0.993 \\
& 5 & 3.389 & 0.530 & 0.994 \\
& Fitting & 3.183 & 0.548 & 0.997 \\
\hline \multirow{4}{*}{$600[23]$} & 4 & 0.887 & 0.480 & 0.985 \\
& 4.5 & 1.096 & 0.582 & 0.998 \\
& 5 & 1.358 & 0.686 & 0.995 \\
& Fitting & 1.117 & 0.628 & 0.998 \\
\hline
\end{tabular}

\section{Conclusions}

Based on the theory of damage mechanics, the rock damage development was regarded as a linear relationship with the cumulative residual strain rate, and the influence of real-time temperature on fatigue damage was considered. The Harris function was introduced to characterize the growth law of rock plastic strain. A novel fatigue damage model was proposed which can reflect the temperature damage and initial fatigue damage and can characterize the whole process of different types of fatigue damage. Damage model parameters $a$ and $b$ can be determined by the fitting method or the two-point method. The correlation degree between the calculated results and the test value is high.

Fatigue life prediction equation was built based on the fatigue damage model and uniaxial compression strain of rock. No matter at which temperature, the calculated fatigue life was very close to the test results, and the maximum error was no more than $5 \%$. The method proposed in this paper can predict the fatigue life at the beginning of fatigue, which can better guide engineering practice.

Damage model parameter analysis shows that the value of parameter $a$ affects the fatigue damage growth rate, which is consistent with the effect of stress ratio fatigue damage. The model parameter $b$ affects the length of steady stage, which is consistent with the effect of temperature on fatigue damage. Therefore, a preliminary conclusion can be made that the parameter $a$ is related to the stress level, while the parameter $b$ indicates the effect of temperature on fatigue damage.

\section{Data Availability}

The datasets used or analyzed during the current study are available from the corresponding author upon reasonable request.

\section{Conflicts of Interest}

The authors declare that there are no conflicts of interest regarding the publication of this paper.

\section{Acknowledgments}

This work was supported by the National Natural Science Foundation of China (Grant nos. 51874144 and 51609266), the Program for New Century Excellent Talents in Fujian
Province University, China, the National Natural Science Foundation of Fujian Province (no. 2018J01630), and the Science and Technology Plan Project in Xiamen, China (Grant no. 3502Z20193040).

\section{References}

[1] Y. Luo, F.-Q. Gong, X.-B. Li, and S.-Y. Wang, "Experimental simulation investigation of influence of depth on spalling characteristics in circular hard rock tunnel," Journal of Central South University, vol. 27, no. 3, pp. 891-910, 2020.

[2] X. Si and F. Gong, "Strength-weakening effect and sheartension failure mode transformation mechanism of rockburst for fine-grained granite under triaxial unloading compression," International Journal of Rock Mechanics and Mining Sciences, vol. 131, p. 104347, 2020.

[3] L. Li, S. Sun, J. Wang, W. Yang, S. Song, and Z. Fang, "Experimental study of the precursor information of the water inrush in shield tunnels due to the proximity of a water-filled cave," International Journal of Rock Mechanics and Mining Sciences, vol. 130, p. 104320, 2020.

[4] J. Yu, G. Liu, Y. Cai, J. Zhou, S. Liu, and B. Tu, "Time-dependent deformation mechanism for swelling soft-rock tunnels in coal mines and its mathematical deduction," International Journal of Geomechanics, vol. 20, no. 3, p. 04019186, 2020.

[5] R. A. Abdula, "Geothermal gradients in iraqi kurdistan deduced from bottom hole temperatures," Egyptian Journal of Petroleum, vol. 26, no. 3, pp. 601-608, 2017.

[6] S. Q. Yang, P. G. Ranjith, H. W. Jing, W. Tian, and Y. Ju, “An experimental investigation on thermal damage and failure mechanical behavior of granite after exposure to different high temperature treatments," Geothermics, vol. 65, pp. 180-197, 2017.

[7] P. K. Gautam, A. K. Verma, S. Maheshwar, and T. N. Singh, "Thermomechanical analysis of different types of sandstone at elevated temperature," Rock Mechanics and Rock Engineering, vol. 49, no. 5, pp. 1985-1993, 2015.

[8] Z.-N. Zhu, H. Tian, G.-S. Jiang, and W. Cheng, "Effects of high temperature on the mechanical properties of Chinese marble," Rock Mechanics and Rock Engineering, vol. 51, no. 6, pp. 1937-1942, 2018.

[9] S. Wisetsaen, C. Walsri, and K. Fuenkajorn, "Effects of loading rate and temperature on tensile strength and deformation of rock salt," International Journal of Rock Mechanics and Mining Sciences, vol. 73, pp. 10-14, 2015.

[10] Y. Chen, J. Zuo, B. Guo, and W. Guo, "Effect of cyclic loading on mechanical and ultrasonic properties of granite from maluanshan tunnel," Bulletin of Engineering Geology and the Environment, vol. 79, no. 1, pp. 299-311, 2020.

[11] Y. Shen, B. Gao, X. Yang, and S. Tao, "Seismic damage mechanism and dynamic deformation characteristic analysis of mountain tunnel after wenchuan earthquake," Engineering Geology, vol. 180, pp. 85-98, 2014.

[12] W. Liang, C. Zhang, H. Gao, X. Yang, S. Xu, and Y. Zhao, "Experiments on mechanical properties of salt rocks under cyclic loading," Journal of Rock Mechanics and Geotechnical Engineering, vol. 4, no. 1, pp. 54-61, 2012.

[13] K. Peng, J. Q. Zhou, Q. L. Zou, and X. Song, "Effect of loading frequency on the deformation behaviours of sandstones subjected to cyclic loads and its underlying mechanism," International Journal of Fatigue, vol. 131, p. 105349, 2020.

[14] K. Peng, J. Zhou, Q. Zou, and F. Yan, "Deformation characteristics of sandstones during cyclic loading and unloading with varying lower limits of stress under different confining 
pressures," International Journal of Fatigue, vol. 127, pp. 82-100, 2019.

[15] Y. Guo, C. Yang, and H. Mao, "Mechanical properties of Jintan mine rock salt under complex stress paths," International Journal of Rock Mechanics and Mining Sciences, vol. 56, pp. 54-61, 2012.

[16] R. Yong, J. Ye, B. Li, and S.-G. Du, "Determining the maximum sampling interval in rock joint roughness measurements using Fourier series," International Journal of Rock Mechanics and Mining Sciences, vol. 101, pp. 78-88, 2018.

[17] J. Fan, J. Chen, D. Jiang, A. Chemenda, J. Chen, and J. Ambre, "Discontinuous cyclic loading tests of salt with acoustic emission monitoring," International Journal of Fatigue, vol. 94, pp. 140-144, 2017.

[18] D. Jiang, J. Fan, J. Chen, L. Li, and Y. Cui, "A mechanism of fatigue in salt under discontinuous cycle loading," International Journal of Rock Mechanics and Mining Sciences, vol. 86, pp. 255-260, 2016.

[19] S.-Q. Yang and B. Hu, "Creep and long-term permeability of a red sandstone subjected to cyclic loading after thermal treatments," Rock Mechanics and Rock Engineering, vol. 51, no. 10, pp. 2981-3004, 2018.

[20] P. Wang, T. Yin, X. Li, S. Zhang, and L. Bai, "Dynamic properties of thermally treated granite subjected to cyclic impact loading," Rock Mechanics and Rock Engineering, vol. 52, no. 4, pp. 991-1010, 2019.

[21] C.-C. Xia, S.-W. Zhou, P.-Y. Zhang, Y.-S. Hu, and Y. Zhou, "Strength criterion for rocks subjected to cyclic stress and temperature variations," Journal of Geophysics and Engineering, vol. 12, no. 5, pp. 753-763, 2015.

[22] R. Song, B. Yue-Ming, Z. Jing-Peng, J. De-yi, and Y. Chun-he, "Experimental investigation of the fatigue properties of salt rock," International Journal of Rock Mechanics and Mining Sciences, vol. 64, pp. 68-72, 2013.

[23] G. K. Zhao, Y. Q. Hu, P. H. Jin et al., "Experimental study on mechanical properties of granite subjected to temperature and cyclic stress," Chinese Journal of Rock Mechanics and Engineering, vol. 38, no. 5, pp. 927-937, 2019, in Chinese.

[24] H. P. Xie, Y. Ju, and Y. L. Dong, “"Discussion about "elastic modulus method" in the classic definition of damage," Mechanics and Practice, vol. 19, no. 2, pp. 1-5, 1997, in Chinese.

[25] Y. Wang, L. Ma, P. Fan, and Y. Chen, "A fatigue damage model for rock salt considering the effects of loading frequency and amplitude," International Journal of Mining Science and Technology, vol. 26, no. 5, pp. 955-958, 2016.

[26] J. Liu, H. Xie, Z. Hou, C. Yang, and L. Chen, "Damage evolution of rock salt under cyclic loading in unixial tests," Acta Geotechnica, vol. 9, no. 1, pp. 153-160, 2014.

[27] J.-Q. Xiao, D.-X. Ding, G. Xu, and F.-L. Jiang, "Inverted S-shaped model for nonlinear fatigue damage of rock," International Journal of Rock Mechanics and Mining Sciences, vol. 46, no. 3, pp. 643-648, 2009.

[28] J.-Q. Xiao, X.-T. Feng, D.-X. Ding, and F.-L. Jiang, "Investigation and modeling on fatigue damage evolution of rock as a function of logarithmic cycle," International Journal for Numerical and Analytical Methods in Geomechanics, vol. 35, no. 10, pp. 1127-1140, 2011.

[29] Y. Liu and F. Dai, "A damage constitutive model for intermittent jointed rocks under cyclic uniaxial compression," International Journal of Rock Mechanics and Mining Sciences, vol. 103, pp. 289-301, 2018.

[30] Y. Li, D. Jia, Z. Rui, J. Peng, C. Fu, and J. Zhang, "Evaluation method of rock brittleness based on statistical constitutive relations for rock damage," Journal of Petroleum Science and Engineering, vol. 153, pp. 123-132, 2017.
[31] H. Pan and H. X. Qiu, "Fatigue model of concrete based on continuum damage mechanics," Journal of Southeast University, vol. 36, no. 4, pp. 605-608, 2006, in Chinese.

[32] S. W. Zhou, C. C. Xia, Y. S. Hu, Y. Zhou, and P. Y. Zhang, "Damage modeling of basaltic rock subjected to cyclic temperature and uniaxial stress," International Journal of Rock Mechanics and Mining Sciences, vol. 77, pp. 163-173, 2015.

[33] X. Xu, Z. F. Gao, and Z. Zhang, "Thermo-mechanical coupling damage constitutive model of rock based on the hoek-brown strength criterion," International Journal of Damage Mechanics, vol. 27, no. 8, pp. 1213-1230, 2017. 